\title{
Evaluación de deglución a través de fibroscopía óptica
}

\author{
Fiberoptic endoscopic evaluation of swallowing
}

Constanza Beltrán $M^{1}$, Bernardita Soler $L^{2}$, Mané León $M^{3}$.

\section{DESCRIPCIÓN DEL PROCEDIMIENTO}

\section{1.- Materiales a utilizar}

- Nasofibroscopio de 3,5 mm con cámara y monitor

- Oximetazolina 0.05\%

- Jalea de color rojo o verde (Figura 1)

- Galletas (Figura 1)

- Agua o jugo (Figura 1)

- Azul de metileno (se utiliza para teñir alimentos)

\section{2.- Participantes necesarios para realizar el estudio}

Médico otorrinolaringólogo y fonoaudiólogo.

\section{3.- Método}

Una de las condiciones para realizar la evaluación de deglución con endoscopio flexible de fibra óptica (nasofibroscopio), es que el paciente se encuentre vigil, en posición sentada y sea capaz de responder órdenes. Se aplican 2 inhalaciones de oximetazolina $0,05 \%$ en cada fosa nasal para lograr un paso fácil de la fibra por la nariz. No se debe usar dimecaína para no producir anestesia laríngea. Posteriormente se tiñen la jalea y el líquido con azul de metileno.

\section{4.- Procedimiento}

Se introduce el nasofibroscopio por la fosa nasal más despejada, hasta el nivel del velo del paladar (Figura 2). Se observan fosas nasales, rinofaringe y laringe, poniendo especial énfasis en: el cierre velofaríngeo, estado de la musculatura faríngea, habilidad del paciente para manejo de secreciones y la abducción y aducción de las cuerdas vocales, lacual se examina solicitando al paciente la emisión de la vocal «e» en forma sostenida En el caso de dudar si existe una paresia cordal, se pide que paciente repita el

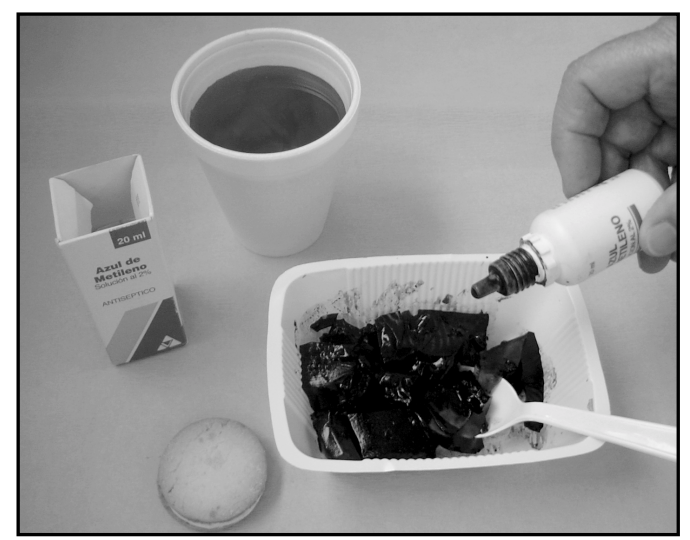

Figura 1. Eementos para evaluación de deglución.

\footnotetext{
${ }^{1}$ Médico, Departamento de Otorrinolaringología de la Pontificia Universidad Católica de Chile.

2 Interna de Medicina de la Universidad de los Andes.

${ }^{3}$ Fonoaudióloga, Departamento de Otorrinolaringología de la Pontificia Universidad Católica de Chile.
} 
sonido «jejeje». Posteriormente, se evalúa la sensibilidad laríngea tocando el repliegue ariepiglótico para evaluar el reflejo laríngeo aductor, esto también se puede realizar mediante la inyección de aire (técnica de ÆESST: Fexible endoscopic evaluation of swallowing with sensory test).

De manera paralela, el fonoaudiólogo se encuentra al costado del paciente para observar el proceso de preparación y masticación del bolo, necesarios para su propulsión del alimento hacia el esófago. Este proceso debe ser rápido, con una duración aproximada de 8 a20 segundos dependiendo de la consistencia del alimento.

$\mathrm{Si}$ en la laringe observamos abundantes secreciones que ocupan la supraglotis, glotis, comisura posterior o senos piriformes, que penetran y caen espontáneamente hacia la subglotis, se suspende el examen, por existir aspiración evidente.

Si no se observan los hallazgos anteriores, se prosigue con el examen.

Al paciente se le da una cucharadita de jalea y se observa qué ocurre con ella durante su avance hacia el esfínter esofágico superior.

\section{5. - Interpretación}

En un proceso de deglución normal, la jalea no debe observarse en la laringe mientras el paciente traga Además, debe evidenciarse coordinación entre el ascenso laríngeo y el paso del alimento.

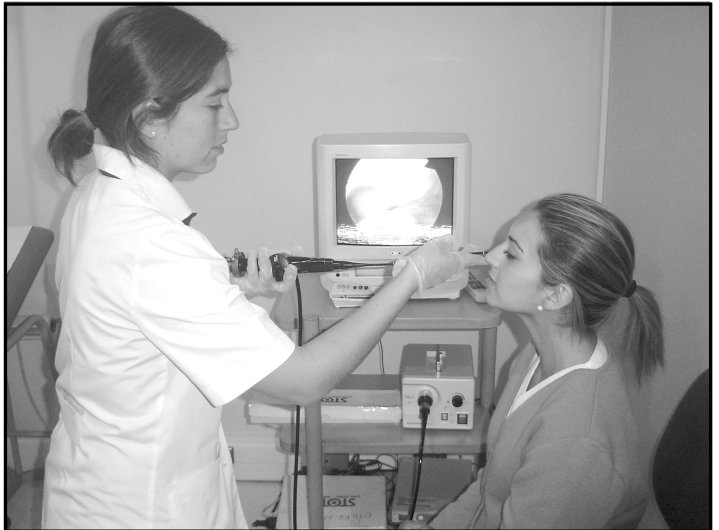

Figura 2: Realización de evaluación de deglución

En un trastorno de deglución se pueden observar las siguientes alteraciones:

a) Enlentecimiento o ausencia de las fases I y II de la deglución: en este caso la formación del bolo y la propulsión del alimento se hace en forma lenta y descoordinada o incluso no existe. Esto lleva al escurrimiento del alimento hacia vallécula, senos piriformes y comisura posterior.

b) Penetración laringea: saliva o jalea se posan el la glotis, sin traspasarla, con o sin reflejo de tos.

c) Aspiración laringea: el alimento espontáneamente atraviesa la glotis hacia la vía aérea.

Esta evaluación se repite para cada tipo de alimento (jalea, galletas y líquidos). De esta forma uno pudiera clasificar funcionalmente la alteración de la deglución en:

a) Leve cuando se observa enlentecimiento o ausencia de la fase I y II de la deglución.

b) Moderada si se evidencia penetración laríngea

c) Severa si existe aspiración.

Dirección: Dra. Constanza Beltrán

Institución: Departamento de Otorrinolaringología. Pontificia Universidad Católica de Chile. Marcoleta 352, $2^{\circ}$ piso, Santiago Centro. Gudad: Santiago

Teléfono: 354-3484 ó 354-3339

E-mail: mbeltran@med.puc.cl 